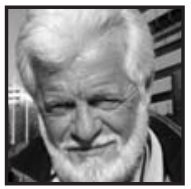

\title{
Higher Learning, Meager Earnings
}

Terry Mosher

\section{ABSTRACT}

This cartoon, a favourite of mine, was drawn for Maclean's Magazine to illustrate a column written by Paul Wells on the subject of university professors trying to survive on their often meager earnings.

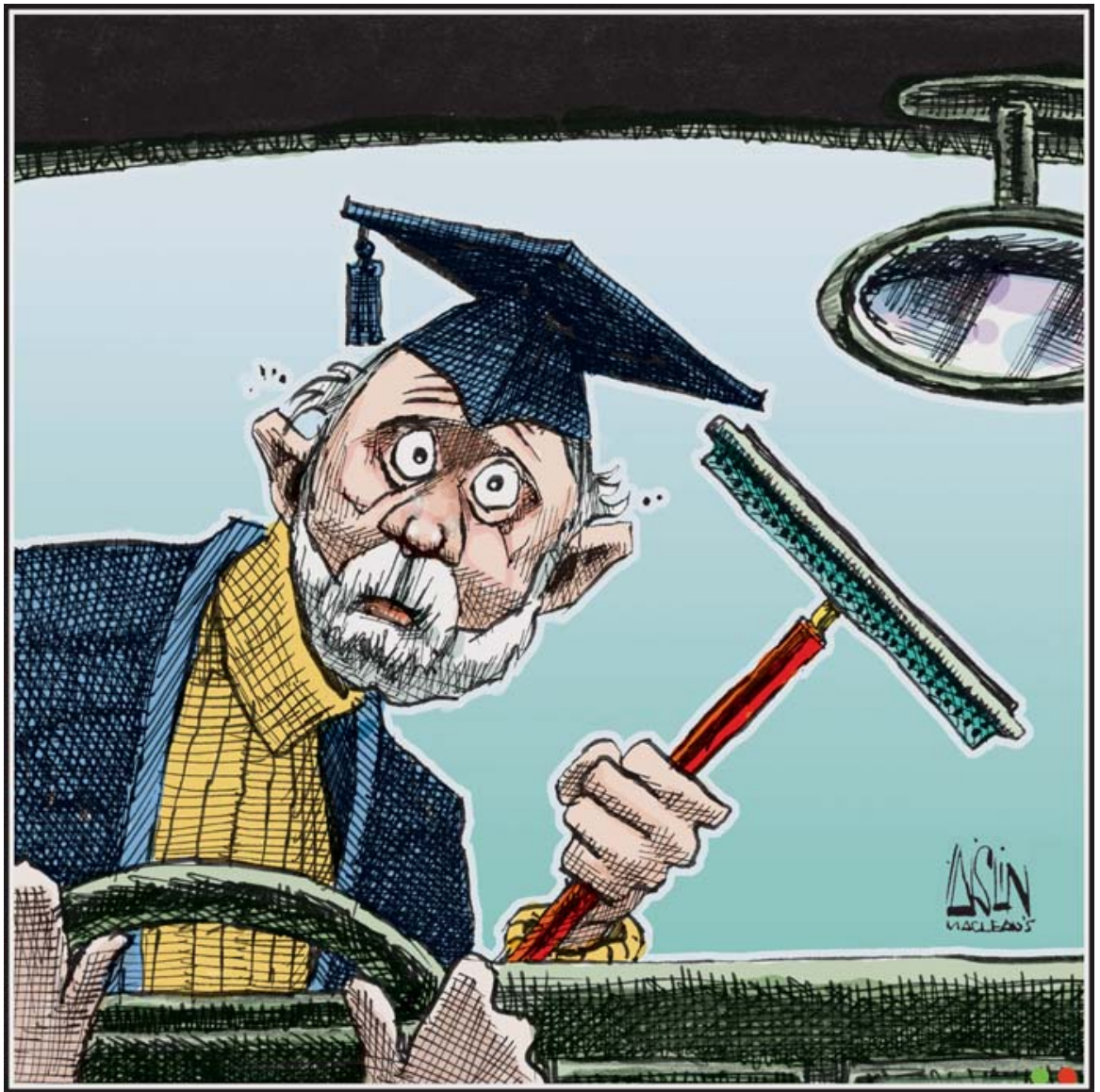




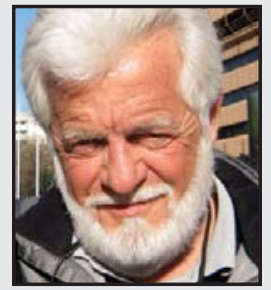

AISLIN is the name of Terry Mosher's elder daughterand the nom de plume he has used for over thirty-five years as the political cartoonist for Montreal's English-language newspaper, The Gazette. To date, forty-two Aislin books have been published. His latest collection of cartoons is entitled AISLIN'S SHENANIGANS.

Over the course of his career, Terry Mosher has frequently appeared as a commentator on many of Canada's major television and radio programs. He is also a regular speaker on humour and the importance of cartooning as a communications tool. In recognition of both his charitable work and his contribution to the world of political cartooning, Mosher was named an Officer of the Order of Canada in May 2003. In 2007, Terry received an honorary Doctor of Letters from Montreal's McGill University.

Filmmaker John Curtin won the Gemini for best Canadian biography documentary of 2007 for his Life and Times documentary on Terry Mosher entitled, Dangerous When Provoked.

LINKTO:

www.aislin.com 